\title{
DESIGUALDADES DE GÉNERO EN LA MEDICALIZACIÓN: UN TORTUOSO RECORRIDO POR EL VADEMÉCUM
}

\author{
Lourdes Pérez González \\ Universidad de Oviedo \\ lourdes@uniovi.es
}

Recibido: 09-02-2010

Aceptado: 26-03-2010

\section{Resumen:}

Análisis de las diferencias de género en la medicalización —entendida como la apropiación de parcelas de la vida cotidiana por el ámbito médico/farmacéutico - y sus repercusiones en la vida y la salud de las mujeres. Este análisis utiliza como referencia fundamental el Vademécum, base de datos que nos ha permitido la búsqueda de los fármacos (centrándonos en los efectos adversos y las interacciones) que se expiden sin receta y están destinados fundamentalmente, o únicamente, a las mujeres "sanas".

Palabras clave: Medicalización, género, Vademecum.

\begin{abstract}
Analysis of gender differences in medicalization - understood as the appropriation of daily life areas by the medical/pharmaceutical field - and their impact on women's health and lives. This study relies on the Vademecum as the main reference, database that has allowed us the search of drugs (focusing on the adverse effects and the interactions) that are given without a prescription and are basically, or only, addressed to "healthy" women.
\end{abstract}

Key words: Medicalization, gender, Vademecum. 


\section{Introducción}

"Somos distintos, somos iguales. Pero en la calle nadie lo sabe..." ",

El término medicalización no figura en el Diccionario de la Real Academia Española; pero eso no significa que no designe una realidad bien concreta, en expansión, y para la que hemos encontrado, no sin dificultad, una definición que puede servir como punto de partida:

"Los estudios sobre la medicalización la presentan como un proceso por el que ciertos fenómenos que formaban parte de otros campos, como la educación, la ley, la religión, etc., han sido redefinidos como fenómenos médicos. El diccionario de salud pública de Kishore conceptualiza la medicalización como "la forma en que el ámbito de la medicina moderna se ha expandido en los años recientes y ahora abarca muchos problemas que antes no estaban considerados como entidades médicas". Y añade que incluye una gran variedad de manifestaciones, como las fases normales del ciclo reproductivo y vital de la mujer (menstruación, embarazo, parto, menopausia), la vejez, la infelicidad, la soledad y el aislamiento por problemas sociales, así como la pobreza o el desempleo" (Marquez y Meneu, 2007: 67).

También Pierre Boitte analiza el concepto de medicalización:

“[...] mientras más los objetivos de la medicina son definidos por los actores médicos, más los problemas sociales son parte integrante de la atención médica y de la terapia médica y más una medicalización de la sociedad está en curso (en el sentido que el modelo tecnocientífico de la medicina interviene en el

\footnotetext{
${ }^{1}$ El Emigrante: canción, Celtas cortos.
} 
diagnóstico y en la «resolución» de problemas sociales cada vez más numerosos)" (Boitte, 2001: 17).

Hablar de medicalización nos remite, pues, a control, a intervención, a dominación de la salud, entendida como la definió en 1946 la OMS en su Constitución: "estado de completo bienestar físico, mental y social, y no solamente la ausencia de infecciones o enfermedades" (OMS, 2006: 1). Pero ese control — casi podríamos decir, esa colonización-, como cualquier balance contable, tiene su activo y su pasivo, sus beneficios y sus costes, aunque desigualmente repartidos; es decir, los beneficios repercuten fundamentalmente en las empresas farmacéuticas que, cuantos más fármacos vendan, mayor rentabilidad obtienen, mientras los costes recaen en la sociedad, no sólo en términos económicos (coste material de los medicamentos) sino también en términos de salud (ninguna medicación es inocua y mucho menos si se utiliza reiteradamente.

¿Recaen sobre toda la sociedad igual? Evidentemente no. Las empresas farmacéuticas dirigen sus dardos a las sociedades occidentales e industrializadas (variables de clase y geográfica), como ya advirtió la propia OMS (2009: 95) "La galopante mercantilización de la salud y la comercialización de la atención sanitaria tienen su origen en la creciente medicalización de las enfermedades humanas y sociales, y en las diferencias cada vez mayores y más contrastantes entre el escaso uso de los servicios que hacen los pobres y el exceso de uso de los ricos en todo el mundo [...]". Y a las mujeres (variable de género), también según la OMS, fundamentalmente en el embarazo "Una cuestión que a menudo se pasa por alto es la excesiva medicalización, impulsada por la oferta, de que son objeto los embarazos normales, a veces por razones de lucro. Una atención sobremedicalizada puede perjudicar innecesariamente la salud tanto de la madre como de su hijo y exponer a las familias a gastos evitables."

Es decir, la medicalización es un proceso generalizado y en expansión, como ya hemos dicho, pero sesgado por variables de clase, geográficas y de género o, lo que es lo mismo: afecta, perjudica y lesiona fundamentalmente a las mujeres occidentales u occidentalizadas. Por eso, el propósito de este trabajo es analizar cómo se va 
introduciendo la medicalización en la vida de una mujer "normal" y cómo le irá afectando, en comparación con la vida de un varón también "normal".

\section{Metodología}

“...Si el error cierra una puerta es para que otra quede abierta... ,2

Dado que nuestro propósito era aproximarnos a cómo y hasta qué punto la medicalización incide en la vida cotidiana de una mujer "normal", hemos utilizado como libro fundamental de cabecera el Vademécum. ¿Por qué el Vademécum? Porque se define a sí mismo en su página web, como "el medio de información de medicamentos, sustancias, principios activos, dopaje, interacciones, equivalencias internacionales y laboratorios farmacéuticos más completo de España”; se le supone, por tanto, rigor, exactitud y generalidad. Además, es de acceso libre en línea (previo registro mediante un correo electrónico y una contraseña).

El Vademécum ofrece varios criterios de búsqueda:

- Medicamento

- $\quad$ Principios activos

- Laboratorios

- $\quad$ Enfermedades

- Noticias

- Equivalencias

- Interacciones

En cada preparado aparece información organizada por:

- Datos generales (equivalente al prospecto de la medicina)

- Ficha completa

- $\quad$ Prospecto

\footnotetext{
${ }^{2}$ De par en par: canción, Luis Eduardo Aute.
} 
- Mostrar interacciones: Muy graves, Potencialmente graves, Controvertidas, Teóricas o anecdóticas, Pendiente de calificar

- Equivalencias internacionales

- Dopaje/deporte

Vamos a recordar brevemente las situaciones en las que se pueden producir interacciones, utilizando para ello los criterios de la U.S. Food and Drug Administration:

“- La interacción de una medicina con otra ocurre cuando dos o más medicinas no se pueden mezclar. Esta interacción de "medicina con medicina" puede causar un efecto secundario inesperado [...]

- Las interacciones de medicinas con alimentos o bebidas [...]

- La interacción de una medicina con un estado físico existente puede ocurrir cuando una condición médica reacciona negativamente a ciertas medicinas, haciéndolas posiblemente peligrosas [...]" (U.S. Food and Drug Administration, 2009).

Es decir, el efecto de un fármaco puede verse aumentado (sobredosis) o disminuido (falta de utilidad terapéutica por infradosificación) por otro fármaco, la ingesta de ciertos alimentos o bebidas, o una situación especial del organismo (hipertensión, deshidratación...) y el riesgo de aparición de una interacción farmacológica aumenta en función del número de fármacos administrados al mismo tiempo a un paciente.

El Vademécum, además, permite filtrar las búsquedas por varios criterios (embarazo, lactancia, fotosensibilidad, conducción de vehículos, farmacovigilancia, receta, financiación y dopaje en el deporte) de los que hemos utilizado tres:

1) Farmacovigilancia (que se indica, si es el caso, con un triángulo amarillo):

- Medicamento autorizado en los últimos 5 años

- Medicamento autorizado hace más de 5 años 
2) Receta:

- Uso exclusivo hospitalario

- Diagnóstico hospitalario

- Receta estupefacientes

- Receta médica

- Sin receta

3) Financiación

- Financiación restringida

- No financiada

- Aportación reducida por el beneficiario

Las etapas recorridas para realizar este trabajo han sido las siguientes:

- Búsqueda en el apartado "enfermedades" de aquellas sólo asignadas a mujeres (tipo: menopausia, dismenorrea...) (variable género).

- Selección de las que pueden ser no patológicas, es decir aquellas que se corresponden con molestias habituales y que no requerirían consulta médica (por ejemplo: descartamos todas las que sean secundarias...) (variable medicalización).

- Utilización con los fármacos que se expiden para esas "enfermedades" del filtro "receta", para seleccionar únicamente los medicamentos que se expiden sin receta; es decir, no requieren una consulta médica, sino que están al alcance de cualquiera (variable automedicación).

- Utilización posteriormente del filtro "financiación" para seleccionar los preparados que corren enteramente a costa del consumidor, sin financiación en ningún caso por parte del sistema sanitario, lo que quiere decir, en principio, que ningún médico los recetaría, ya que tiene a su alcance otros fármacos financiados (variable rentabilidad).

- Utilización del filtro "farmacovigilancia" que nos servirá, como veremos seguidamente, para conocer si la oferta de la empresa farmacéutica está suficientemente experimentada o no, ya que bajo ese apartado aparecen los fármacos aprobados en los últimos 5 años (variable garantía). 
- Utilización del criterio "mostrar interacciones" para detectar las posibles consecuencias adversas de la utilización del fármaco y visualizar las posibles sinergias o antagonismos (variable adecuación).

Es decir, pretendemos bucear en el vademécum para descubrir la medicalización de género, con un sesgo de automedicación inducida y a cargo de la consumidora, y sus riesgos potenciales para la salud.

\section{Vacuna del papiloma humano}

"Golpe a golpe... se hace camino al andar...",

Esta historia se sitúa en cualquier lugar del territorio español (también podría ser en otro lugar de algún país de la UE) y tiene como protagonistas a un niño y una niña recién nacidos en las condiciones habituales. Ambos van creciendo sanos y sin problemas, como certifican las visitas pediátricas periódicas planificadas por su centro de salud.

A los 16 años, dejan de ser atendidos por los servicios de pediatría y pasan, ambos, a depender de un médico de familia. Sin embargo, la niña - primera desigualdad - desde el año pasado (2009), cuando se incorporó al calendario, llega a los 16 años con una vacuna más ${ }^{4}$, que se administra entre los 11-14 años en tres dosis.

Aunque este fármaco se expide con receta, dado que es prescriptivo (aunque no obligatorio), merece un comentario, así que vamos a detenernos brevemente en esta primera desigualdad.

Primera sorpresa: en "medicamentos" no aparece dicha vacuna bajo el epígrafe "vacuna” o "vacunación”; tampoco en "enfermedades" aparece en "papiloma".

\footnotetext{
${ }^{3}$ Se hace camino al andar: Antonio Machado.

${ }^{4}$ Prevención del cáncer de cérvix relacionados con los tipos 16 y 18 del VPH / Prevención del carcinoma cervical relacionado con los tipos $6,11,16$ y 18 del VPH .
} 
Apurando un poco más introducimos "papiloma humano" y "virus” y ahí sí aparecen las siguientes entradas:

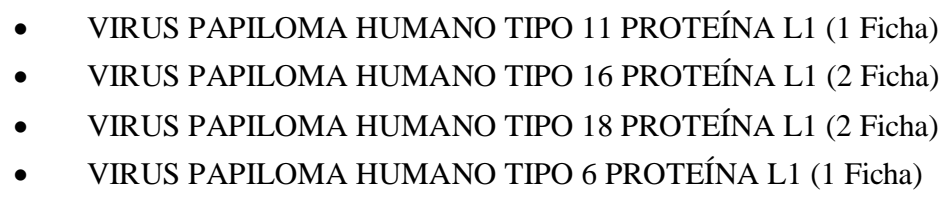

Como en este caso partíamos de la ventaja de conocer el nombre de los dos únicos preparados que existen, recibimos la segunda sorpresa al comprobar que el actualmente utilizado en nuestro país, Gardasil, con dos presentaciones (GARDASIL Susp. iny. en jeringa precargada / GARDASIL Susp. iny. en vial) figura bajo cuatro epígrafes de "enfermedades":

1. Prevención de condiloma acuminata relacionado con los tipos 6, 11, 16 y 18 del VPH.

2. Prevención de displasia cervical (CIN 2/3) relacionada con los tipos 6, 11, 16 y 18 del VPH.

3. Prevención de lesiones displásicas vulvares (VIN 2/3) relacionadas con los tipos 6, 11, 16 y 18 del VPH.

4. Prevención del carcinoma cervical relacionado con los tipos 6, 11, 16 y 18 del VPH.

Pinchamos en "Mostrar interacciones" y dice: Ninguna interacción detectada. Entramos en la ficha del fármaco para conocer las "Reacciones adversas" y constatamos que son las propias de cualquier vacuna inyectada: Pirexia; en el lugar de iny.: eritema, dolor, hinchazón, hematoma, prurito. No obstante, para cerciorarnos de que todo es tan inofensivo como parece, abrimos la pestaña "Noticias" y aparecen 13 desde el 16/11/2006 al 23/02/2010, cuyos titulares reproducimos en orden cronológico:

1- 16/11/2006 | General: PREMIOS. Expertos internacionales premian Gardasil® 2- 12/12/2006 | General: FARMACOLOGÍA. Gardasil®, la primera vacuna que previene el cáncer de cuello de útero, mantiene en el tiempo su alta eficacia

3- 07/02/2007 | General: FARMACOLOGÍA. Gardasil previene también 
lesiones precancerosas de vulva y vagina

4- 17/04/2007 | General: FARMACOLOGÍA. Gardasil, la primera vacuna que previene el cáncer de cuello de útero, premiada por su excelente evaluación coste-beneficio

5- 04/10/2007 | General: INDUSTRIA FARMACÉUTICA. GARDASIL y JANUVIA, del laboratorio Merck \& Co. Inc., obtienen el máximo galardón de los Premios Galien EE.UU.

6- 05/11/2007 | General: TERAPIAS. Gardasil protege a la mujeres de 24 a 45 años frente al cáncer de cuello de útero

7- 01/10/2008 | General: TERAPIAS. Gardasil@, la vacuna tetravalente para la prevención del cáncer de cuello uterino empieza a cumplir sus promesas dos años después de su aprobación

8- 11/02/2009 | General: ALERTAS. Gardasil suspensión inyectable en jeringa precargada. Suspensión del lote NH52670 (CN 658978)

9- 23/02/2009 | General: ALERTAS. Nota informativa seguridad de la vacuna al virus del Papiloma humana GARDASIL®

10- 23/02/2009 | General: ALERTAS Seguridad de la vacuna frente al virus del papiloma humano GARDASIL®: revisión en Europa

11- 28/04/2009 | General: ALERTAS

12- 22/02/2010 | General: FARMACOLOGÍA. Desinmovilización y devolucion del lote NH52670 de Gardasil Un nuevo estudio confirma la eficacia de Gardasil para prevenir enfermedades genitales en mujeres adultas 13- 23/02/2010 | Especialidades farmacéuticas. GARDASIL.

Decidimos abrir la última noticia, la del 23 de este mes de febrero y comprobamos con sobresalto - que pronto se convirtió en alarma- que el título de este trabajo cobraba todo su sentido porque el camino por el vademecun no sólo era tortuoso sino que rozaba lo maquiavélico: es aquí dónde en un extensísimo documento aparecen los "efectos adversos" y donde descubrimos que la vacuna en cuestión:

- No presenta interacciones, no porque no las tenga sino porque se desconocen, ya que todavía no ha sido suficientemente experimentada, al tener menos de cinco años; de ahí que esté en farmacovigilancia. 
- Sus efectos adversos no son meramente locales como indicaba la ficha oficial, sino que son de amplísimo espectro, aún por conocer y determinar (Anexo I).

¿Qué será de las futuras mujeres, hoy niñas ya medicalizadas con una vacuna cuyo alcance y repercusiones se desconocen?

\section{Menstruaciones, síndrome premenstrual}

“Resistiré, para seguir viviendo...",

El niño y la niña van creciendo sanos y sin problemas; la niña llega a la edad de la menarquia (oscila entre los 10 y los 16 años en los países occidentales) y, a pesar de que es un hecho fisiológico - como la espermarca de los varones - puede suscitar diversos tipos de manifestaciones aptos para ser medicalizados.

Nuestra protagonista tiene sus reglas regulares y normales, pero de vez en cuando, le "duelen los ovarios" o nota los pechos hinchados. Podría acudir a un médico o ginecólogo pero considera que son molestias "lógicas" y decide tomar alguno de los preparados destinados a ello por su cuenta o por recomendación de alguien que ya los ha tomado; esto nos permitirá analizar únicamente los epígrafes en los que figuran preparados que se expiden sin receta.

Nos remitimos a la terminología del vademécum donde aparecen, por orden alfabético, en el epígrafe "enfermedades", las siguientes:

1. Alivio de hinchazón y tensión dolorosa mamaria del síndrome premenstrual y de irritabilidad derivada de estos síntomas $\left(3\right.$ preparados $\left.^{6}\right)$ todos sin receta, ninguno financiado.

2. Alivio del dolor debido a dismenorrea primaria (13 preparados), 5 sin receta, 4 no financiados.

\footnotetext{
${ }^{5}$ Resistiré: canción, Dúo Dinámico.

${ }^{6}$ Mencionamos el total de los que figuran en el vademécum, aunque se trate de un mismo preparado pero con diferentes presentaciones.
} 
3. Dismenorrea (182 preparados $\left.^{7}\right)(69$ sin receta), 38 no financiados.

4. Premenstrual, síndrome (8 preparados), 2 sin receta, ambos no financiados.

Dada la cantidad de preparados bajo estos cuatro epígrafes que remiten a la menstruación, optamos por agruparlos por principios activos de lo que resulta:

\section{Agnus-cactus exto. $\mathrm{Seco}^{8}$}

2. Acido acetil-salicílico ${ }^{9}$ Con diferentes combinaciones:

I. Acido acetil-salicílico, cafeína anhidra ${ }^{10}$

II. Ácido acetilsalicílico, Cafeína, Gelsemium sempervirens exto., Paracetamol ${ }^{11}$

III. Ácido acetilsalicílico, glicina ${ }^{12}$

IV. Ácido acetilsalicílico, glicina, cafeína ${ }^{13}$

V. Ácido acetilsalićlico, ácido ascórbico, Clorfenamina maleato, Nuez kola exto. Seco ${ }^{14}$

VI. Acido acetil-salicílico, cafeína, paracetamol ${ }^{15}$

VII. Acido acetil-salicílico, ácido ascórbico ${ }^{16}$

3. Paracetamol ${ }^{17}$. Y sus combinaciones:

I. Paracetamol, propifenazona, cafeína ${ }^{18}$

II. Paracetamol, Cafeína anhidra, Dimenhidrinato ${ }^{19}$

4. Ibuprofeno ${ }^{20}$. Y una combinación:

\footnotetext{
${ }^{7}$ Hemos de indicar que el vademécum incluye aquí todo tipo de analgésicos generales.

${ }^{8}$ Mestrodol, Premedol, Vitelaf.

${ }^{9}$ A.A.S., Aspirina, Sedergine.

${ }^{10}$ Cafiaspirina.

${ }^{11}$ Novocafeinol.

${ }^{12}$ Okaldol.

${ }^{13}$ Okaldol con cafeína.

${ }^{14}$ Rimagrip complex.

${ }^{15}$ Actron compuesto.

${ }^{16}$ Acyflox, Aspirina C.

${ }^{17}$ Coflumol, Dafalgan, Efetamol, Eferalgan, Gelocatil, Panadol efervescente, Paracetamol Abex, Paracetamol Benel, Paracetamol Combix, Paracetamol Dermogen, Paracetamol Edigen, Paracetamol Farmalider, Paracetamol CERN Pharma, EFG, Paracetamol Liderfeme, Paracetamol Normon EFG, Paracetamol Oensa, Paracetamol Qualigen EFG, Paracetamol Sandoz, Paracetamol Winadol, Termalgin, Xumadol.

${ }^{18}$ Melabon.

${ }^{19}$ Saldeva.

20 Advil, Espididol, Fenospin, Ibulaf, Ibuprofeno Alcala Farma, Ibuprofeno Farmsierra, Ibuprofeno Gayoso, Liderfeme, Liderfen, Narfen, Nurofen (lisina), Ratiodol, Todalgil.
} 
I. Ibuprofeno, Cafeína, Dimenhidrinato ${ }^{21}$

5. Naproxeno 22

6. Vitamina A, Vitamina $\mathrm{E}^{23}$

Procediendo como en el epígrafe anterior, buscamos las interacciones de los principales principios activos y sus reacciones adversas.

Agnus-cactus exto. Seco:

- Ninguna interacción detectada.

- $\quad$ Reacciones adversas: Prurito.

Acido acetilsalicílico:

- Se han encontrado 711 interacciones.

- Reacciones adversas: Véase Advertencias y precauciones Además: hipoprotrombinemia, rinitis, espasmo bronquial paroxístico, disnea, hemorragia gastrointestinal, dolor abdominal, náuseas, dispepsia, vómitos, úlcera gástrica/duodenal, urticaria, erupción, angioedema. Interrumpir tto. si aparece sordera, tinnitus o mareos.

- Advertencias y precauciones: Ingestión habitual de alcohol (riesgo de hemorragia gástrica), deficiencia de G6PD, urticaria, rinitis, HTA, ancianos. No tomar antes (1 sem) o después de extracción dental o cirugía, ni en caso de gota, metrorragias o menorragias. Riesgo de hemorragia, ulceración y perforación del tramo digestivo alto. Evitar asociar a fármacos que aumentan riesgo de hemorragia. No usar sistemáticamente como preventivo de molestias de vacunación. Insuficiencia hepática.

Paracetamol:

- Se han encontrado 137 interacciones.

\footnotetext{
${ }^{21}$ Salvarina.

${ }^{22}$ Anaprox, Momen.

${ }^{23}$ Auxina A+E.
} 
- Reacciones adversas: Raras: malestar, nivel aumentado de transaminasas, hipotensión, hepatotoxicidad, erupción cutánea, alteraciones hematológicas, hipoglucemia, piuria estéril.

- Precaución. Uso ocasional aceptable, pero la administración prolongada de dosis elevadas aumenta el riesgo de aparición de efectos renales adversos.

Ibuprofeno:

- Se han encontrado 915 interacciones.

- Reacciones adversas: Dispepsia, diarrea, náuseas, vómitos, dolor abdominal; erupción cutánea; fatiga o somnolencia, cefalea, mareo, vértigo.

\section{Naproxeno:}

- Se han encontrado 579 interacciones.

- Reacciones adversas. Oral: molestias abdominales, dolor epigástrico, cefaleas, náuseas, edema periférico moderado, aumento tensión arterial, zumbido de oídos, vértigo, somnolencia. Rectal: tenesmo, proctitis, hemorragia vaginal o sensación de molestia, dolor, ardor o picor.

\section{Cafeína:}

- No aparece el epígrafe interacciones.

- Reacciones adversas: Insomnio, agitación, excitación; náuseas, vómitos, diarrea, gastralgia, cefalea, tinnitus, desorientación, extrasístoles, palpitaciones, taquicardia, arritmia cardiaca, irritabilidad, sofocos, taquipnea, poliuria. Con dosis altas: cuadros de neurosis y ansiedad.

Es muy posible que a lo largo del período fértil de su vida, esta mujer haya tenido varios episodios de molestias premenstruales o menstruales y que las haya aliviado (la vida empuja y la publicidad abruma...) con alguno de estos fármacos, cuyas interacciones y efectos adversos no son pocos; eso sí, son variados (Anexo II).

¿Qué será de las mujeres, impulsadas a medicalizarse para que afronten "mejor" el día a día, sus responsabilidades y cargas? 


\section{Anticoncepción de emergencia}

“Una piedra en el camino..., 24

Nuestra ya mujer, a lo largo de su vida fértil (con relaciones sexuales) ha tenido la posibilidad de recorrer varios itinerarios:

- No utilizar ningún anticonceptivo y procrear (esta posibilidad está siendo objeto de un estudio específico).

- Utilizar anticonceptivos orales con o sin procreación (esta posibilidad incluye controles y prescripciones médicos que no son el objeto de este trabajo).

- Utilizar anticonceptivos de barrera que no necesitan ningún control médico (posibilidad en la que vamos a centrarnos).

Pero ha habido al menos un fallo; decide, entonces, utilizar anticoncepción de emergencia y, para ello, dispone de cinco preparados, todos ellos sin receta y cuatro no financiados:

- $\quad$ ELLAONE Comp. $30 \mathrm{mg}$

- $\quad$ NORLEVO Comp. $1500 \mathrm{mcg}$

- POSTINOR Comp. $1500 \mathrm{mcg}$

- $\quad$ POSTINOR Comp. $750 \mathrm{mcg}$

- $\quad$ VIKELA Comp. $1500 \mathrm{mcg}$

Salvo el primero, cuyo principio activo es Ulipristal, el resto comparten la misma composición: Levonorgestrel, así que nos lo han puesto bastante fácil.

Ulipristal:

- Interacciones: Ninguna interacción detectada. Pero..., en efecto, no se han realizado estudios específicos de interacciones con otros medicamentos in vivo. Figura bajo farmacovigilancia.

\footnotetext{
${ }^{24}$ El Rey: canción, José Alfredo Jiménez.
} 
- Reacciones adversas (en ficha completa - datos clínicos- reacciones adversas) (Anexo III).

Levonorgestrel:

- Se han encontrado 313 interacciones.

- Reacciones adversas: Comp.: náuseas, dolor hipogástrico; fatiga; cefalea; sangrado no relacionado con menstruación.

- Implante: depresión, modificaciones del estado de animo y libido; migrañas; palpitaciones, dolor torácico; HTA, venas varicosas; disnea; molestias abdominales; acné, dermatitis de contacto, alopecia, hipertricosis, exantema, prurito, cambios de pigmentación; síntomas urinarios; vaginitis, quistes ováricos, nódulos mamarios benignos, secreción mamaria; picor en lugar de inserción, dolor de espalda, pérdida de peso.

En cualquiera de los caso, es una solución cara (y no sólo económicamente): en el mejor de los casos 313 interacciones (por muy sana que esté probablemente ya haya tenido que medicarse por alguna causa), más alguna de las al menos 300 que llevaba anteriormente, sin contar las reacciones adversas (alguna le habrá tocado por mucha suerte que tenga...).

¿Qué será de las mujeres en las que recae exclusivamente el peso de la concepción o la anticoncepción, a costa de sus costes? 


\section{Menopausia}

"Voy camino a los cincuenta, punto y coma de la vida...,

Con la llegada del climaterio vuelve a poder recorrer varios itinerarios:

- Acudir a una unidad de menopausia, donde es posible que le aconsejen fármacos con receta (objeto también de otro estudio) o incluso la TSH (que, por cierto, no figura como tal, sino como "menopausia - histerectomizadas-) a pesar de que es objeto de una alerta del la Agencia Española de Medicamentos y Productos Sanitarios del 13-02-2008.

- Considerar que las molestias de la menopausia son "lógicas" y hay que pasarlas, tratando de paliarlas con preparados sin receta.

En este último caso hay dos epígrafes del Vademécum que recogen los siguientes preparados:

- Menopausia (climaterio femenino) 79 preparados (de los cuales 28 se dispensan sin receta), 26 no financiados.

- Sofocos (molestias asociadas al climaterio) con 36 preparados (34 sin receta), 31 no financiados.

Los principios activos de los fármacos englobados en la categoría Menopausia (climaterio femenino) son:

- Isoflavonas de soja ${ }^{26}$

- Interacciones: Actividad atenuada por: antibióticos.

- Advertencias y precauciones: No administrar con tumores hormonodependientes (falta de estudios).

- $\quad$ Cimicífuga racemosa exto. $\operatorname{Seco}^{27}$, que ya habíamos visto en el epígrafe 3.

\footnotetext{
${ }^{25}$ Voy camino a los cincuenta: canción, Cacho Castaño.

${ }^{26}$ Aquiflav, Bluna, Cexel, Devogin, Extracto De Glycine Max Toll Pharma, Fitoladius, Flavia, Flavodrei-Efp, Flojalaf, Glycine Max Devon, Malena. Menoclim, Ortosoy, Osarlaf, Phito Soya, Pleginer, Primsoja, Ratiofemin, Sobeyan.

${ }^{27}$ Avala, Fluxilan, Klimadynon.
} 
- Acidum phosphoricum, Ignatia, Kalium bromatum, Sepia officinalis, Zincum isovalerianicum ${ }^{28}$.

- Interacciones: no se han descrito.

- Efectos adversos: no se han descrito.

- Glycine max merr exto. seco, Trifolium pratense exto ${ }^{29}$.

- Interacciones: 4.

- Contraindicaciones: Hipersensibilidad a alguno de los componentes.

- Advertencias y precauciones. Falta de estudios en mujeres con tumores hormono-dependientes. No corrige deficiencia hipoestrogénica menopáusica.

- Jalea real, Panax ginseng, Vitamina $\mathrm{E}^{30}$.

- Interacciones: 12.

- Efectos adversos: No se conocen. Comunique a su médico o farmacéutico cualquier reacción adversa que pueda atribuir a este medicamento.

En cuanto a los preparados incluidos en la categoría Sofocos (molestias asociadas al climaterio), de los 34 sin receta, sólo 10 son distintos a los que acabamos de ver, con los principios activos siguientes:

- Cimicífuga racemosa exto. Seco ${ }^{31}$

- Glycine max merr exto. seco, Trifolium pratense exto ${ }^{32}$

- Isoflavonas de soja ${ }^{33}$.Con sus variantes:

- Calcio, Isoflavonas de soja exto., Vitamina D3 ${ }^{34}$

- Isoflavonas de soja exto., Valeriana officinalis ${ }^{35}$

Más de lo mismo, la verdad, para este viaje no necesitábamos alforjas, casi

\footnotetext{
${ }^{28}$ Nervoheel N.

${ }^{29}$ Soyred.

${ }^{30}$ Vitestable.

${ }^{31}$ Aquicimix, Extracto de Cimifuga Alacan. Menopasol.

${ }^{32}$ Equilgyn, Fitogyn.

${ }^{33}$ Fisiogen, Isorose.

${ }^{34}$ flavocalcio D.

${ }^{35}$ Flavovaleriana.
} 
podríamos decir que el "no es lo mismo basta o va a estar... 36 " de la canción, en este caso al parecer, sí es lo mismo. De todas formas nos llama la atención que:

- La Cimicífuga racemosa exto. Seco sirve para tanto aliviar el síndrome premenstrual como la menopausia $(i !)$.

- Las Isoflavonas de soja, casi omnipresentes, y otros principios activos utilizados no parecen estar suficientemente estudiados, dada la escasa información que figura de ellos, de hecho se trata de medicamentos autorizados en los últimos cinco años ("farmacovigilancia"). Sin embargo son objeto de una amplia y extensa comercialización y promoción.

- Aproximadamente el 90\% (no hemos hecho el cálculo exacto) de estos preparados no están financiados, es decir, se pagan íntegros.

¿Qué será de las mujeres ya tan farmacodependientes y con una larga vida por delante?

\section{Conclusiones}

“Qué será, será...? El futuro está por ver...”37

Hemos hecho este hipotético recorrido por la vida de esta mujer sana para poder entender qué pasa cuando una dolencia que estime "anormal" -dolores músculo-esquelético, problemas respiratorios, infecciones, trastornos del sueño, problemas gastro-intestinales, problemas vasculares- (sin entrar en patologías más graves) la lleve a una consulta médica; a la pregunta habitual: ¿Toma usted algún medicamento? responderá que no, porque ni tan siquiera es consciente de ello, tan habitual se ha hecho ya el recurso a ciertos fármacos ampliamente anunciados para aliviar todo tipo de molestias (en muchos casos creadas).

Pero en el mejor de los casos, que es la hipótesis de la que partíamos, lleva dentro

\footnotetext{
${ }^{36}$ No es lo mismo: canción, Alejandro Sanz.

${ }^{37}$ ¿Qué será?: canción, Doris Day.
} 
un cóctel de preparados que inevitablemente han tenido que influir en su organismo y cuyo efecto acumulativo es imposible de determinar. ¿Y qué ha pasado con el varón una vez que acabó su etapa pediátrica?

Si no se produce ningún problema de salud, ninguna patología ni ningún accidente o incidente, el varón no tendrá contacto con el sistema sanitario hasta que entre en algún programa de prevención de próstata, previstos a partir de los 40 años (aunque por lo general los varones se preocupan de la próstata bastante más tarde). Es decir, la vida del varón discurre en paralelo al sistema sanitario, no cruzándose hasta que lo requiera una patología. En términos de medicalización, que es lo que nos interesa, si su estado de salud es adecuado podría pasar un largo tramo de su vida sin haber ingerido ningún fármaco. Es decir, mientras el varón, de los 16 a los 40 y pico no está medicalizado, salvo caso de necesidad, la mujer tiene una alta probabilidad de estarlo sin demasiada necesidad.

Hasta hace relativamente poco era fundamentalmente la vida sexual y reproductiva la que estaba medicalizada; en palabras de la OMS:

“[...] en todas partes del mundo, a lo largo de la historia, las mujeres han tenido la responsabilidad de su salud -parto, anticoncepción y aborto-. Durante los últimos siglos, la profesionalización de la atención de la salud desplazó el control femenino de estos procesos. Se considera a los médicos y los científicos como la personificación del conocimiento sobre la salud y el cuerpo humano. Procesos naturales como el parto han sido medicalizados, y el control de las mujeres sobre éstos ha sido minimizado. Las parteras empíricas, quienes durante siglos han atendido a las mujeres en el embarazo y el parto, han sido marginalizadas [...]" (OMS, 2001:170).

Ahora, las empresas farmacéuticas han ampliado su intervención por ambos extremos (antes de la menarquia y durante y después de la menopausia); somos una amplia, excelente y fructífera clientela: cuanto antes se nos fidelice mayores serán los beneficios 
económicos, cuanta más densa sea la tela de medicalización que nos envuelve, más tendremos que consumir, además haciendo de conejillos de indias no sólo no pagadas sino pagando.

¿Qué será de mujeres de las que dicen las estadísticas que su esperanza de vida es mayor? omitiendo, callando, ocultando que su calidad de vida es peor... probablemente porque la industria farmacéutica obtiene de una cada vez más amplia clientela femenina (variable género) una parte importante de beneficios (variable rentabilidad) poniendo a su disposición una serie de preparados sin requisito médico previo (variable automedicación), cuya experimentación en muchos casos está en curso (variable garantía), con los consiguientes costes para la salud (variable adecuación), por lo general difícilmente detectables a corto y medio plazo.

Porque esta es una desigualdad de género casi invisible: no se puede cuantificar — como las desigualdades de salario o de acceso al mundo laboral—o denunciar — como las desigualdades de trato o de promoción- o negociar — como las desigualdades en el reparto de tareas y cuidados- No, pero sí se puede destapar para poder incorporarla a la agenda de salud de las mujeres, lo que nos permitirá posicionarnos colectiva y firmemente frente y contra esta agresión.

“... cada aspecto de naturaleza de las mujeres es una ocasión para la responsabilidad, la toma de decisiones, el ejercicio de su libertad en definitiva. "38

\footnotetext{
${ }^{38}$ Victoria Sau: Ser mujer, el fin de una imagen tradicional.
} 


\section{BIBLIOGRAFÍA}

“La memoria y el olvido dan fe de vida ... „39

- Boitte, P. (2001): "El envejecimiento, oportunidad para una medicina en busca de sus finalidades". En Acta Bioética, año VII, no 1 pp 9-25, [en línea] Disponible en http://www.scielo.cl/scielo.php?pid=S1726569X2001000100002\&script=sci_arttext [24/02/2010].

- Márquez, S. y Meneu, R (2007): “La medicalización de la vida y sus protagonistas". En Eikasia. Revista de Filosofía, II 8 (enero 2007) pp. 65-86, [en línea] Disponible en: http://www.revistadefilosofia.org [26/02/2010].

- Organización Mundial de la Salud (2001): "Transformando los sistemas de salud: género y derechos en salud reproductiva".

- Organización Mundial de la Salud (2005): "Informe sobre la salud en el mundo 2005".

- Organización Mundial de la Salud: Documentos básicos (Oct. 2006): “Constitución de la Organización Mundial de la salud 1946”, [en línea] Disponible en: http://www.who.int/governance/eb/constitution/es/ [26/02/2010].

- Organización Mundial de la Salud, Comisión sobre Determinantes sociales de la Salud (2009): "Subsanar las desigualdades en una generación".

- Vademécum, [en línea] Disponible en: http://www.vademecum.es/ [26/02/2010].

- Sau, V. (1981): Diccionario ideológico feminista, volumen I. Barcelona: Icaria. . (1986): Ser mujer, el fin de una imagen tradicional. Barcelona: Icaria. . (2001): Diccionario ideológico feminista, volumen II. Barcelona: Icaria.

- U.S. Food and Drug Administration (2009) "Las interacciones de medicamentos", [en línea] Disponible en: http://www.fda.gov/Drugs/ResourcesForYou/ucm079505.htm [Acceso 26/02/2010].

- Valls Llobet, C. (2006): Mujeres invisibles. Barcelona: Nuevas ediciones de bolsillo. . (2009): Mujeres, salud poder. Valencia: Cátedra.

\footnotetext{
${ }^{39}$ Fe de vida: canción, Juan Manuel Serrat.
} 


\section{ANEXo I}

“... Es ligero equipaje para tan largo viaje... ${ }^{40}$

\section{GARDASIL}

\section{Suspensión inyectable}

Vacuna frente al Virus del Papiloma Humano [Tipos 6, 11, 16, 18] (Recombinante, adsorbida).

Reacciones adversas. Durante 6 ensayos clínicos ( 5 controlados con placebo)... (6.996 mujeres de 9 a 45 años de edad y 1.072 chicos de 9 a 15 años de edad en el momento del reclutamiento) y 5.966 recibieron placebo.

Las siguientes reacciones adversas relacionadas con la vacuna fueron observadas entre los vacunados con Gardasil [...]

Trastornos musculoesqueléticos y del tejido conjuntivo:

Frecuentes: dolor en las extremidades.

Trastornos generales y alteraciones en el lugar de administración:

Muy frecuentes: pirexia.

Muy frecuentes: en el lugar de inyección: eritema, dolor, hinchazón.

Frecuentes: en el lugar de inyección: hematoma, prurito.

$[\ldots]$

Experiencia post-comercialización.

Se han notificado espontáneamente acontecimientos adversos en la etapa de postcomercialización de Gardasil que no se han enumerado anteriormente.

No es posible estimar la frecuencia para todos los acontecimientos ni establecer una relación causal con la exposición a la vacuna, ya que éstos fueron notificados voluntariamente por una población de tamaño indeterminado.

Trastornos de la sangre y del sistema linfático: linfadenopatía.

Trastornos del sistema inmunológico: reacciones de hipersensibilidad, incluyendo reacciones anafilácticas/anafilactoides.

Trastornos del sistema nervioso: síndrome de Guillain-Barré, mareo, dolor de cabeza, síncope acompañado algunas veces de movimientos tonicoclónicos.

Trastornos gastrointestinales: náuseas, vómitos.

Trastornos musculoesqueléticos y del tejido conjuntivo: artralgia, mialgia.

Trastornos generales y alteraciones en el lugar de administración: astenia, escalofríos, fatiga, malestar.

\footnotetext{
${ }^{40}$ Un beso y una flor: canción, Nino Bravo.
} 


\section{ANEXO II}

Efectos adversos de preparados para dolores premenstruales y dismenorrea

\begin{tabular}{|c|c|c|c|c|c|}
\hline & $\begin{array}{c}\text { Acido } \\
\text { acetilsalicílico } \\
\text { R. A. } 711\end{array}$ & $\begin{array}{c}\text { Paracetamol } \\
\text { R.A. } 137\end{array}$ & $\begin{array}{l}\text { Ibuprofeno } \\
\text { R.A. } 915\end{array}$ & $\begin{array}{c}\text { Naproxeno } \\
\text { R.A. } 579\end{array}$ & + CAFEÍNA \\
\hline $\begin{array}{l}\text { T. metabolismo y } \\
\text { nutrición }\end{array}$ & & $\begin{array}{c}\text { Elevación } \\
\text { transaminasas } \\
\text { Hepatotoxicidad } \\
\text { Hipoglucemia }\end{array}$ & & & \\
\hline $\begin{array}{l}\text { T. del sistema } \\
\text { nervioso }\end{array}$ & & & $\begin{array}{c}\text { Mareo } \\
\text { Cefalea } \\
\text { Somnolencia }\end{array}$ & $\begin{array}{c}\text { Cefaleas } \\
\text { Somnolencia }\end{array}$ & $\begin{array}{c}\text { Insomnio } \\
\text { Cefalea }\end{array}$ \\
\hline $\begin{array}{l}\text { T. del oído y del } \\
\text { laberinto }\end{array}$ & $\begin{array}{c}\text { Sordera, tinnitus, } \\
\text { mareos }\end{array}$ & & Vértigo & $\begin{array}{c}\text { Zumbido } \\
\text { oídos } \\
\text { Vértigo }\end{array}$ & tinnitus \\
\hline $\begin{array}{l}\text { T. cardio- } \\
\text { vasculares }\end{array}$ & $\begin{array}{l}\text { Hipoprotrombine } \\
\text { mia (problemas de } \\
\text { coagulación) }\end{array}$ & $\begin{array}{l}\text { Hipotensión } \\
\text { Alteraciones } \\
\text { hematológicas }\end{array}$ & & $\begin{array}{c}\text { Edema } \\
\text { periférico } \\
\text { moderado } \\
\text { Hipertención }\end{array}$ & $\begin{array}{c}\text { extrasístoles } \\
\text { palpitaciones } \\
\text { taquicardia } \\
\text { arritmia } \\
\text { cardiaca } \\
\text { sofocos }\end{array}$ \\
\hline T. respiratorios, & $\begin{array}{c}\text { Rinitis } \\
\text { Espasmo } \\
\text { bronquial } \\
\text { paroxístico } \\
\text { disnea }\end{array}$ & & & & taquipnea \\
\hline
\end{tabular}




\begin{tabular}{|c|c|c|c|c|c|}
\hline $\begin{array}{c}\mathrm{T} . \\
\text { gastrointestinales }\end{array}$ & $\begin{array}{c}\text { Hemorragia } \\
\text { gastrointestinal } \\
\text { Dolor abdominal } \\
\text { Náuseas } \\
\text { Dispepsia } \\
\text { Vómitos } \\
\text { Úlcera } \\
\text { gástrica/duodenal }\end{array}$ & & $\begin{array}{c}\text { Dispepsia } \\
\text { Diarrea } \\
\text { Náuseas } \\
\text { Vómitos } \\
\text { Dolor } \\
\text { abdominal }\end{array}$ & $\begin{array}{l}\text { Molestias } \\
\text { abdominales } \\
\text { Dolor } \\
\text { epigástrico } \\
\text { Náuseas }\end{array}$ & $\begin{array}{l}\text { Náuseas } \\
\text { Vómitos } \\
\text { Diarrea } \\
\text { gastralgia }\end{array}$ \\
\hline $\begin{array}{l}\text { T. de la piel y del } \\
\text { tejido subcutáneo }\end{array}$ & $\begin{array}{c}\text { Urticaria } \\
\text { Erupción } \\
\text { angioedema }\end{array}$ & $\begin{array}{c}\text { Erupción } \\
\text { cutánea }\end{array}$ & $\begin{array}{c}\text { Erupción } \\
\text { cutánea }\end{array}$ & & \\
\hline $\begin{array}{l}\text { T. músculo- } \\
\text { esquelético y tejido } \\
\text { conjuntivo }\end{array}$ & & & & & \\
\hline $\begin{array}{c}\text { T. renales y } \\
\text { urinarios }\end{array}$ & & Piuria estéril & & & Poliuria \\
\hline $\begin{array}{c}\text { T. aparato } \\
\text { reproductor y } \\
\text { mama }\end{array}$ & & & & & \\
\hline T. estado ánimo & & & & & $\begin{array}{c}\text { Irritabilidad } \\
\text { Agitación } \\
\text { Excitación } \\
\text { Desorientación } \\
\text { Neurosis } \\
\text { (dosis altas) } \\
\text { Ansiedad } \\
\text { (dosis altas) }\end{array}$ \\
\hline T. generales & & Malestar & Fatiga & & \\
\hline
\end{tabular}

(Elaboración propia) 


\section{ANEXo III}

\section{Extracto de ficha técnica de Ellaone}

La seguridad del acetato de ulipristal se ha evaluado en 3.391 mujeres en ensayos en fase II y III. En la Tabla siguiente se indican las reacciones adversas notificadas en un ensayo en fase III de 1.533 mujeres $[\ldots]$

\begin{tabular}{|c|c|c|c|c|}
\hline MedDRA & \multicolumn{4}{|c|}{ Reacciones adversas (frecuencia) } \\
\hline $\begin{array}{l}\text { Clasificación de } \\
\text { órganos y sistemas }\end{array}$ & $\begin{array}{c}\text { Muy } \\
\text { frecuentes }\end{array}$ & Frecuentes & Poco frecuentes & Raras \\
\hline $\begin{array}{l}\text { Infecciones e } \\
\text { infestaciones }\end{array}$ & & Infecciones $* *$ & & \\
\hline $\begin{array}{c}\text { Trastornos } \\
\text { metabolismo y } \\
\text { nutrición }\end{array}$ & & & $\begin{array}{l}\text { Trastornos del } \\
\text { apetito }\end{array}$ & Deshidratación \\
\hline $\begin{array}{c}\text { Trastornos } \\
\text { psiquiátricos }\end{array}$ & & $\begin{array}{c}\text { Trastornos del } \\
\text { estado de } \\
\text { ánimo }\end{array}$ & $\begin{array}{c}\text { Depresión } \\
\text { Síntomas de } \\
\text { ansiedad } \\
\text { Insomnio } \\
\text { Trastornos libido } \\
\text { Irritabilidad }\end{array}$ & \\
\hline $\begin{array}{c}\text { Trastornos del } \\
\text { sistema nervioso }\end{array}$ & & $\begin{array}{l}\text { Cefalea } \\
\text { Mareos }\end{array}$ & $\begin{array}{c}\text { Somnolencia } \\
\text { Temblor }\end{array}$ & $\begin{array}{c}\text { T. atención, Disguesia } \\
\text { Letargo }\end{array}$ \\
\hline Trastornos oculares & & & Visión borrosa & \\
\hline T. oído y laberinto & & & & Vértigo \\
\hline $\begin{array}{l}\text { Trastornos } \\
\text { vasculares }\end{array}$ & & & Sofocos & \\
\hline $\begin{array}{l}\text { Trastornos } \\
\text { respiratorios, } \\
\text { torácicos y } \\
\text { mediastínicos }\end{array}$ & & & & $\begin{array}{l}\text { Congestión sinusal } \\
\text { Tos, Epistaxis } \\
\text { Sequedad garganta }\end{array}$ \\
\hline
\end{tabular}




\begin{tabular}{|c|c|c|c|c|}
\hline $\begin{array}{c}\text { Trastornos } \\
\text { gastrointestinales }\end{array}$ & $\begin{array}{c}\text { Dolor } \\
\text { abdominal }\end{array}$ & $\begin{array}{l}\text { Náuseas } \\
\text { Vómitos } \\
\text { Dispepsia }\end{array}$ & $\begin{array}{c}\text { Diarrea } \\
\text { Estreñimiento } \\
\text { Sequedad de boca } \\
\text { Flatulencia }\end{array}$ & $\begin{array}{c}\text { Enfermedad por reflujo } \\
\text { gastroesofágico } \\
\text { Glositis, Dentalgia }\end{array}$ \\
\hline $\begin{array}{l}\text { Trastornos de la piel } \\
\text { y del tejido } \\
\text { subcutáneo }\end{array}$ & & & $\begin{array}{c}\text { Acné, Exantema } \\
\text { Prurito }\end{array}$ & Urticaria \\
\hline $\begin{array}{c}\text { Trastornos } \\
\text { musculoesqueléticos } \\
\text { y del tejido } \\
\text { conjuntivo }\end{array}$ & & $\begin{array}{l}\text { Espasmos } \\
\text { musculares } \\
\text { Dolor de } \\
\text { espalda }\end{array}$ & $\begin{array}{c}\text { Dolor } \\
\text { musculoesquelético }\end{array}$ & \\
\hline $\begin{array}{c}\text { Trastornos renales y } \\
\text { urinarios }\end{array}$ & & & Polaquiuria & $\begin{array}{c}\text { Nefrolitiasis, Dolor } \\
\text { renal } \\
\text { Cromaturia }\end{array}$ \\
\hline $\begin{array}{c}\text { Trastornos del } \\
\text { aparato reproductor } \\
\text { y de la mama }\end{array}$ & $\begin{array}{l}\text { Trastorno } \\
\text { menstrual }\end{array}$ & $\begin{array}{l}\text { Dismenorrea } \\
\text { Menorragia } \\
\text { Metrorragia }\end{array}$ & $\begin{array}{l}\text { Dolor de mamas } \\
\text { Dolor genital } \\
\text { Espasmo uterino } \\
\text { Síndrome prem. } \\
\text { Prurito genital } \\
\text { Flujo vaginal }\end{array}$ & $\begin{array}{l}\text { Rotura de quiste } \\
\text { ovárico }\end{array}$ \\
\hline $\begin{array}{c}\text { Trastornos } \\
\text { generales y } \\
\text { alteraciones en el } \\
\text { lugar de } \\
\text { administración }\end{array}$ & & Cansancio & Dolor & $\begin{array}{l}\text { Molestias torácicas } \\
\text { Inflamación } \\
\text { Malestar general, } \\
\text { Pirexia } \\
\text { Sed, Escalofríos }\end{array}$ \\
\hline $\begin{array}{r}\text { *Las reaccion } \\
* * \text { Se han notificado } \\
\text { vaginitis bacteriana }\end{array}$ & lversas rara & $\begin{array}{l}\text { las experimer } \\
\text { iones: nasofar } \\
\text { uelo, conjunti }\end{array}$ & $\begin{array}{l}\text { as por sólo uno de ce } \\
\text { tis, infección urinari } \\
\text { infecciosa, enferme }\end{array}$ & $\begin{array}{l}1.533 \text { pacientes. } \\
\text { nfección fúngica, gripe, } \\
\text { d inflamatoria pélvica. }\end{array}$ \\
\hline
\end{tabular}

